\title{
Is $2 \%$ the optimal inflation rate for the Euro Area?
}

\author{
$M^{a}$ Ángeles Caraballo \\ Universidad de Sevilla
}

Tilemahos Efthimiadis

Centre of Planning and Economic Research, Greece

\section{Corresponding author:}

$\mathrm{M}^{\mathrm{a}}$ Ángeles Caraballo.

Universidad de Sevilla. Departamento de Economía e Historia Económica.

Avda. Ramón y Cajal nº1, 41018, Sevilla (Spain).

E-mail: mcaraba@us.es.

Phone: (+34) 954557535 .

Fax: (+34) 954556068 .

\begin{abstract}
According to the relevant literature, monetary policy implications concerning the optimal inflation rate can be derived by examining the relationship between inflation and the Relative Price Variability (RPV). This paper studies this issue for selected Euro Area (EA) countries, using monthly data for the Harmonized Index of Consumer Prices. In particular, semi-parametric estimations are employed so as to find the accurate form of the inflation-RPV relationship. The results indicate that this relationship exhibits a U-shape functional profile. Furthermore, the optimal inflation rates for the EA, France, Germany and Spain are also calculated. For all countries and the EA, we find that although the European Central Bank's "below but close to $2 \%$ " inflation target is optimal for the EA average, it is not the optimum inflation rate for the individual counties.
\end{abstract}

Keywords: Monetary policy, relative price variability, inflation, ECB.

JEL classification: E31, C23 


\section{Introduction}

The main motivation of this paper is to try to answer the question if $2 \%$, the inflation target proposed by the European Central Bank, ${ }^{1}$ is the optimal inflation rate for the Eura Area (EA) as a whole and for three of the largest EA member-countries. Providing a definite answer is challenging as there are many elements that can be taken into account in order to determine the optimal inflation rate. Among them, we focus on the costs of inflation for consumers. On this matter, there is a clear consensus in the literature on the welfare costs caused by the distorting impact of inflation on Relative Price Variability $(R P V)$, given that if an increase in inflation raises the dispersion of prices, the costs of getting accurate information about prices for consumers are going to increase as well. Therefore, the inflation rate that minimizes costs for consumers can be obtained as the one that minimizes $R P V$.

The positive relationship between $R P V$ and inflation has practically become a stylized fact in macroeconomics. From a theoretical point of view, several approaches try to explain the links underlying the relationship between inflation and $R P V$ : search and menu cost models emphasize the role of expected inflation, ${ }^{2}$ while the signal extraction model proposed by Lucas (1973) and Barro (1976) argues that non-neutrality is explained by uncertainty and the extension of the signal extraction model developed by Hercowitz (1981) and Cukierman (1983) implies that the higher unexpected inflation the higher $R P V$, i.e. the key factor is the size of the shock, while the sign of unexpected inflation is irrelevant. Nevertheless, empirical evidence does not support unambiguously any of the above approaches.

From an empirical point of view, as far as the inflation- $R P V$ is concerned, traditional works as Vining and Elwertowski (1976) and Parks (1978) conclude that such relation is linear but there is increasing evidence in favour of a non-linear relationship. ${ }^{3}$ Moreover, recent research presents three types of evidence. Firstly, Nautz and Scharff (2005) for Germany, and Nautz and Scharff (2012) for the EA find that $R P V$ is increasing in inflation even in low inflation environments. Secondly, Bick and Nautz (2008), in a panel threshold model for several USA cities verify positive and negative effects of inflation on $R P V$, while the suggested annual inflation to minimize $R P V$ is in the range of $1,8-2,8 \%$. In this branch, and more important, Fielding and Mizen (2008) for USA, Choi (2010) for USA and Japan and Caraballo and Dabús (2012) for Spain show evidence of a U-shape profile of the inflation- $R P V$ relationship. These findings have relevant implications for monetary policy. If the inflation- $R P V$ relationship is linear, then the lower inflation, the lower the $R P V$ and therefore the optimal inflation rate which minimises the welfare costs of price dispersion is zero. However, this implication is not valid if the inflation- $R P V$ relationship is non-linear, e.g. it exhibits a U-shape. If this is the case, the inflation rate that minimises $R P V$ is positive and therefore reducing inflation beyond a critical point (the minimum of the U-shape) could be harmful (Bruno and Easterly 1998).

In this paper, we analyse the features of the inflation- $R P V$ relationship for the EA as a whole and for selected EA countries for the 1997-2010 period using semiparametric estimations. We also derive the optimal inflation rate that minimises $R P V$ for each country during this period. The main results show that the relationship between inflation and $R P V$ exhibits a U-shape functional profile for all countries examined.

The paper is organized as follows. Section 2 presents a brief description of the data and the variables used. Section 3 discusses the methodologies applied and the empirical results regarding the optimal inflation rates for the EA as a whole, section 4 obtains the optimal inflation for the selected countries Germany, Spain and France. Section 5 concludes.

\footnotetext{
${ }^{1}$ According to the Maastricht treaty (1992), the ECB's main task is to ensure price stability. The ECB defines this task as "the year-on-year increase in the Harmonised Index of Consumer Prices (HICP) for the Euro Area below, but close to 2\% over the medium term" (ECB 2004). However, amongst others, Fendel and Frenkel (2009) find that when EA inflation differentials were high, the ECB was reluctant to combat inflation.

${ }^{2}$ See Sheshinski and Weiss (1977), Rotemberg (1983) and and Caplin and Leahy (1991).

${ }^{3}$ See Caraballo and Dabús (2008) for a review of the literature.
} 


\section{Data and variables}

For the analysis, we use monthly data for the Harmonized Indices of Consumer Prices (HICP). For the purposes of this paper, these indices are more appropriate than Consumer Price Indices (CPI), as HICP are specifically designed for comparisons among EA countries. Furthermore, as the ECB conducts a common monetary policy for the whole monetary union, it refers to the EA HICP when assessing price stability.

Data are provided by Eurostat and cover the EA as a whole (changing composition), ${ }^{4}$ and individual EA countries for the period from January 1997 to October 2010. The individual countries are France (FR), Germany (DE) and Spain (ES) which are three of the four biggest countries in the EA in terms of population and GDP.

The analysis is conducted separately for two sets of data. The first includes the twelve main HICP categories (henceforth 2-digit level) and the other includes further detailed HICP data consisting of 37 subcategories (henceforth 3-digit level). The inflation rate is calculated as the annual log-difference of the HICP. $R P V$ is a measure of the non-uniformity of the variations of individual prices, relative to the average inflation rate. To obtain the $R P V$, a modified version of the coefficient of variation $(\mathrm{CV})$ is implemented using the weighted sum of individual prices inflation rate. At time $t$, the $R P V$ can be defined as follows:

$$
R P V_{t}=\frac{\left(\sum_{i} w_{i t}\left(I N_{i t}-I N_{t}\right)^{2}\right)^{1 / 2}}{\left|1+I N_{t}\right|}
$$

Where $w_{i t}$ is the weight of price $i$ in the price index, $I N_{i t}$ the inflation rate of group $i$ and $I N_{t}$ the overall inflation rate at time $t$. Expression (1) is preferred to the simple variance or standard deviation because it is not spuriously correlated with the mean of the distribution, that is, the inflation rate. Furthermore, this alternative can be defined when inflation is close to zero or in periods of deflation, which is important as the sample used includes countries with low rates of inflation (e.g. Germany). The traditional formula of CV would not be appropriate as it implies that when inflation is near zero, $R P V$ tends to infinity.

The analysis has been carried out with $R P V$ obtained using the 37 subcategories of the HICP. In order to check the robustness of the results, we use $R P V$ obtained with the twelve main HICP categories. Only when both $R P V$ appear, we will distinguish between $R P V-3$ digits and $R P V-2$ digits. $^{5}$

\section{Relative Price Variability and optimal inflation. Results for the EA}

In order to derive the shape of the inflation-RPV function, a partially linear model is applied. ${ }^{6}$ We have estimated the following expression (2):

$$
R P V_{t}=\theta_{1} R P V_{t-1}+\theta_{2} I N_{t-1}+g\left(I N_{t}\right)+\varepsilon_{t}
$$

where $g\left(I N_{t}\right)$ is an unknown smooth differential function that attempts to capture the non-linear impact of inflation on RPV at time $t$. Therefore, the goal is to estimate $g\left(I N_{t}\right)$ in (2). The $g\left(I N_{t}\right)$ function is estimated semi-parametrically in two stages. In the first stage, the parameters $\lambda$ are estimated from the regression equation:

$$
R P V_{t}=\lambda_{1} \overline{R P V}_{t-1}+\lambda_{2} \overline{I N}_{t-1}+\eta_{t}
$$

where $\overline{R P V}_{t-1}$ and $\overline{I N}_{t-1}$ are the residual series from a non-parametric regression of $R P V_{t-1}$ and $I N_{t-l}$ on $I N_{t}$ respectively. In the second stage, the $g\left(I N_{t}\right)$ function is estimated non-parametrically from the regression:

\footnotetext{
${ }^{4}$ As our data sample ends in 2010, Estonia is not included as it joined the EA in 2011.

${ }^{5}$ In other words, in what follows, $R P V$ alone refers to $R P V-3$ digits.

${ }^{6}$ This methodology is similar to that of Fielding and Mizen (2008) and Caraballo and Dabús (2012).
} 


$$
\hat{\eta}_{t}=g\left(I N_{t}\right)+v_{t}
$$

where $\hat{\eta}=R P V_{t}-\lambda_{1} \overline{R P V}_{t-1}-\lambda_{2} \overline{I N}_{t-1}$ In both stages, the regressions are estimated using kernel regressions which are non-parametric techniques that aim to find non-linear relationships between two random variables. In particular, the conditional expectation of random variables is estimated. For the purposes of this paper, the Nadaraya-Watson kernel regression estimator is implemented. As the results of non-parametric regression are very sensitive to the set value of the bandwidth parameter $(b)$, which functions as a smoothing parameter, this parameter is selected using a Mean Squared Forecast Error (MSFE) criterion. Moreover, to derive how the estimation of $g\left(I N_{t}\right)$ is affected by the treatment of extreme values of inflation, an unbounded Gaussian kernel and outlier-robust Epanechnikov, Biweight and Cosinus kernels are used.

Initially, the methodology presented is applied for the EA (changing composition). Figure 1 illustrates the results concerning to MSFE for different values of $b$ in the semiparametric estimation. $^{7}$

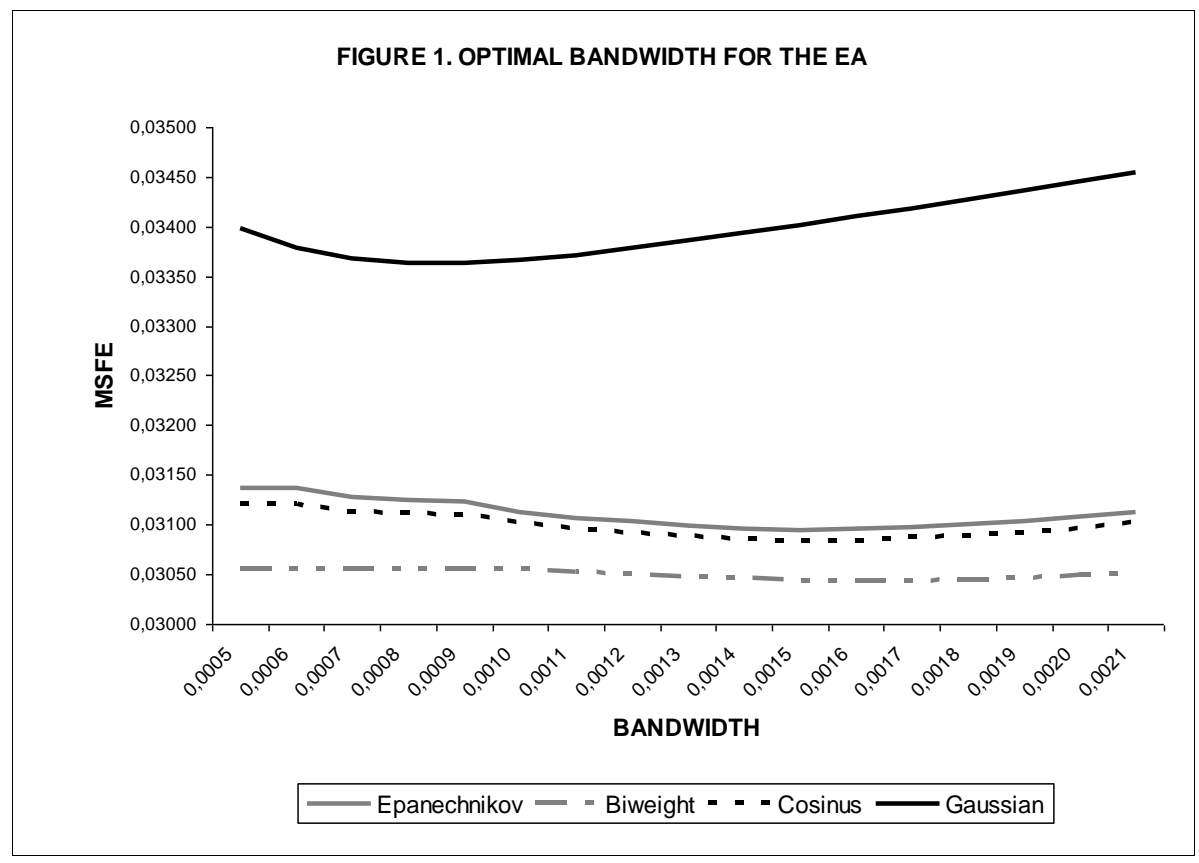

From Figure 1 it is clear that the optimal bandwidth parameter is higher for the three outlier-robust kernels. The optimal bandwidth parameter is 0.0015 for Epanechnikov and Cosinus, 0.0016 for Biweight and 0.0008 for Gaussian. Figure 2 illustrates the $g\left(I N_{t}\right)$ function for the optimal bandwidth for each kernel.

${ }^{7}$ In Figure 1, MSFE has been multiplied by $10^{6}$. 


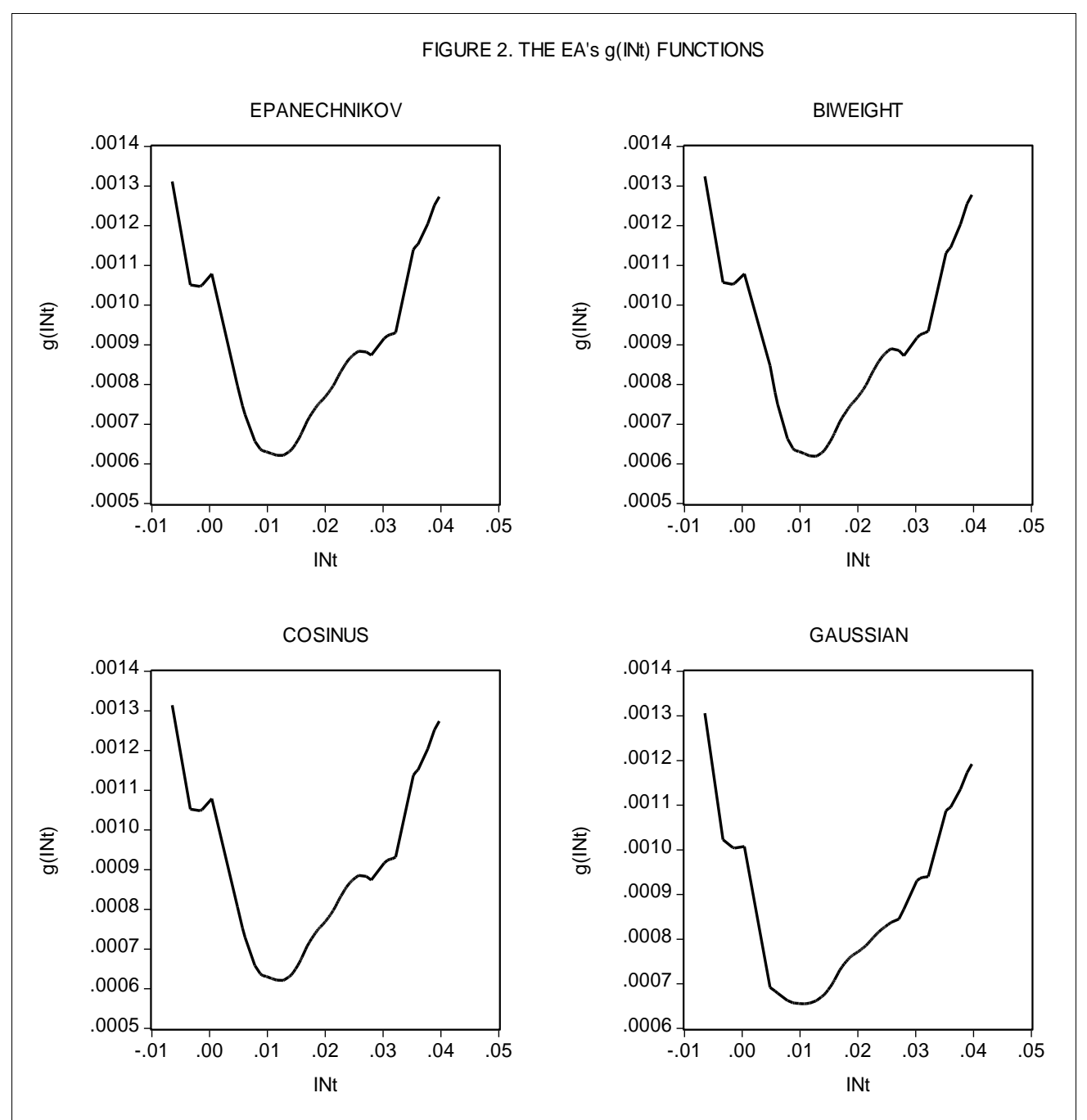

Having estimated $g\left(I N_{t}\right)$, the next step is to calculate the derivative of the $g\left(I N_{t}\right)$ function, as it captures the sensitivity of the $R P V$ to marginal increases in inflation. If $g$ ' $\left(I N_{t}\right)>0$ $\left(g^{\prime}\left(I N_{t}\right)<0\right)$, then $R P V$ is increasing (decreasing) with inflation, while the optimal inflation rate, i.e., the one that minimises $R P V$, is given by $g^{\prime}\left(I N_{t}\right)=0$. To check the robustness of the results, whether they are sensitive to the chosen HICP disaggregation, the same methodology is applied using the 2-digit HICP subcategories. Table 1 summarises the results. 
Table 1. The optimal annual inflation rate for the EA

\begin{tabular}{|c|c|c|c|c|}
\hline & \multicolumn{2}{|c|}{$R P V$ 3-digit level } & \multicolumn{2}{c|}{$R P V$ 2-digit level } \\
\hline Kernel & Optimal bandwidth & Optimal $I N_{t}$ & Optimal bandwidth & Optimal $I N_{t}$ \\
\hline Epanechnikov & 0.0015 & 0.0129 & 0.0016 & 0.0092 \\
\hline Biweight & 0.0016 & 0.0129 & 0.0018 & 0.0089 \\
\hline Cosinus & 0.0015 & 0.0129 & 0.0016 & 0.0092 \\
\hline Gaussian & 0.0008 & 0.0092 & 0.0009 & 0.0061 \\
\hline
\end{tabular}

As it can be seen from Table 1, results are sensitive to the level of disaggregation and to the kernel, more precisely if the kernel is outlier-robust or not. For the remainder of the paper we only use the Epanechnikov kernel function.

Table 2 summarises the results with respect to the effects of changes in time period on optimal inflation. We have considered periods of ten years starting in 1997.01 and periods with different number of years with the same starting point in 1997.01. As Table 2 shows, the optimal inflation rate changes depending on the period considered but it is always between $1 \%$ and $2 \%$.

Table 2. Optimal inflation rate and time period

\begin{tabular}{|c|c|c|c|}
\hline \multicolumn{2}{|c|}{ Periods of ten years } & \multicolumn{2}{c|}{ Periods with different number of years } \\
\hline Period & Optimal $I N_{t}$ & Period & Optimal $I N_{t}$ \\
\hline $1997.01-2006.12$ & 0.0098 & $1997.01-2006.12$ & 0.0098 \\
\hline $1998.01-2007.12$ & 0.0098 & $1997.01-2007.12$ & 0.0098 \\
\hline $1999.01-2008.12$ & 0.0097 & $1997.01-2008.12$ & 0.0098 \\
\hline $2000.01-2009.12$ & 0.0172 & $1997.01-2009.12$ & 0.0129 \\
\hline $2001.01-2010.10$ & 0.0179 & $1997.01-2010.10$ & 0.0129 \\
\hline
\end{tabular}

\section{Optimal inflation for Germany, France and Spain}

Having estimated the optimal inflation rate for the EA, the same rate for the individual countries is also estimated. For all countries the Epanechnikov kernel is used, as it is the most common kernel function used in the relevant literature. Moreover, a number of authors note that it is not the choice of the kernel function that is important, but rather the choice of the bandwidth parameter.

Firstly, we calculate $g(I N t)$ for the period between 1997.01 and 2010.10. The optimal bandwidth is calculated using the same methodology as before. Figures 3, 4 and 5 show the results of the estimation of $g(I N t)$ for Germany, Spain and France respectively, both for the optimal bandwidth for each country (on the left hand side) and using the optimal bandwidth of the EA (on the right hand side). Results for all three countries show that the inflation-RPV relationship exhibits a U-shape function. 

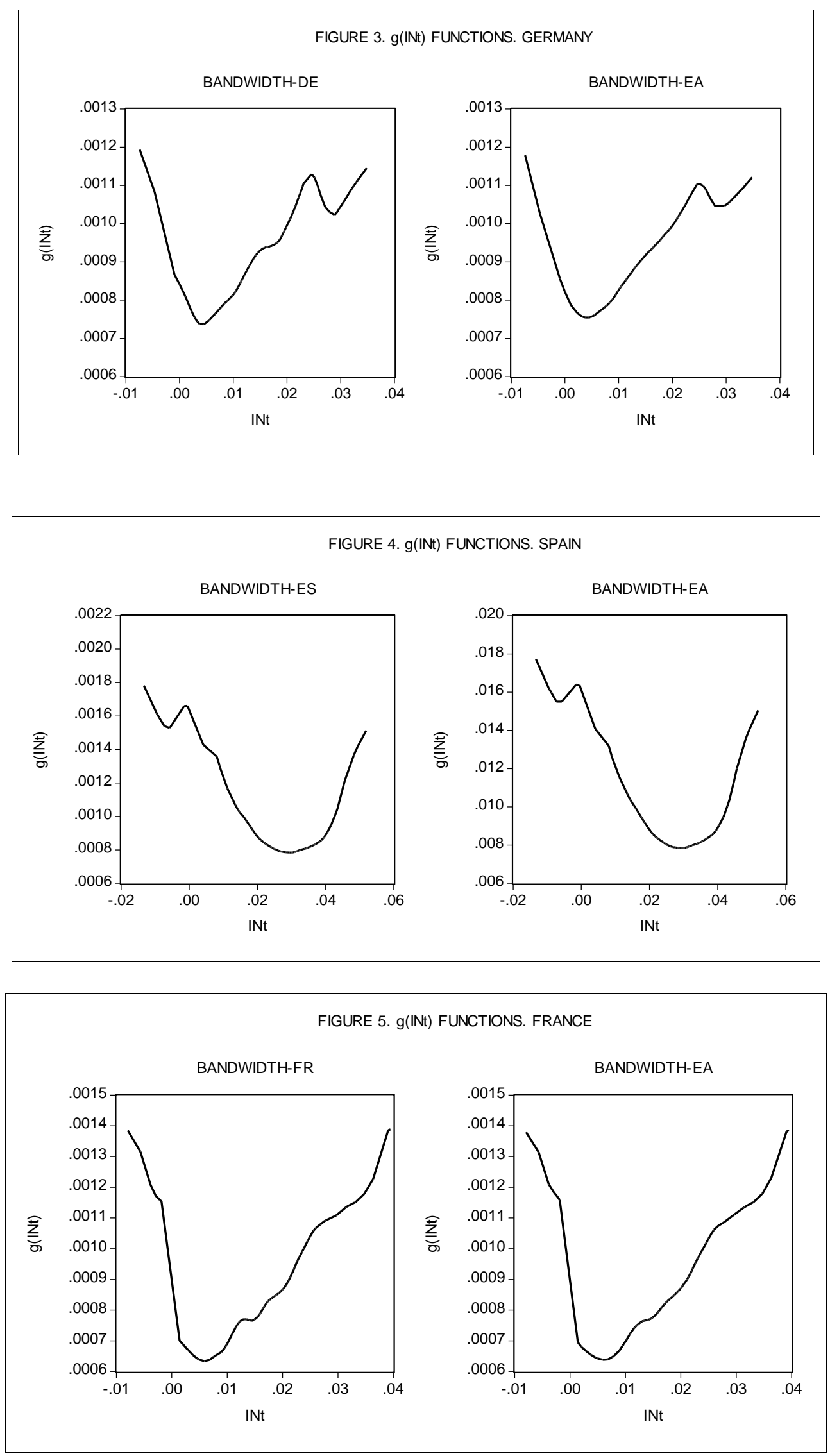

Moreover, to test the robustness of the results we have estimated the optimal bandwidth and the $g$ function for $R P V$ 2-digit level and for the period between 1997.01 and 2010.10. Therefore, from $g\left(I N_{t}\right)$ we obtain $g^{\prime}\left(I N_{t}\right)$ and the optimal inflation rate is calculated. Finally, the optimal 
inflation corresponding to the optimal bandwidth for the EA is estimated for each country. These results are reported in Table 3.

Table 3. Optimal inflation

\begin{tabular}{|c|c|c|c|c|}
\hline & EA & DE & ES & FR \\
\hline IN-Mean & 0.0186 & 0.0143 & 0.0263 & 0.0162 \\
\hline IN-Maximum & 0.0396 & 0.0348 & 0.0518 & 0.0394 \\
\hline IN- Minimum & -0.0064 & -0.0074 & -0.0133 & -0.0079 \\
\hline Std. Dev. & 0.0076 & 0.0077 & 0.0119 & 0.0084 \\
\hline \multicolumn{5}{|c|}{$R P V$ 2-digit } \\
\hline IN-EA & 0.0092 & 0.0054 & 0.0303 & 0.0049 \\
\hline $\mathrm{IN}^{*}$ & & 0.0044 & 0.0303 & 0.0048 \\
\hline MSFE-EA & 0.0177 & 0.0616 & 0.0261 & 0.0148 \\
\hline$b^{*}$ & 0.0016 & 0.0020 & 0.0019 & 0.0009 \\
\hline MSFE* & & 0.0709 & 0.0261 & 0.0147 \\
\hline \multicolumn{5}{|c|}{ RPV 3-digit } \\
\hline IN-EA & 0.0129 & 0.0054 & 0.0303 & 0.0058 \\
\hline $\mathrm{IN}^{*}$ & & 0.0054 & 0.0303 & 0.0059 \\
\hline MSFE-EA & 0.0309 & 0.0842 & 0.0387 & 0.0370 \\
\hline$b^{*}$ & 0.0015 & 0.0010 & 0.0012 & 0.0013 \\
\hline MSFE* & & 0.0838 & 0.0375 & 0.0365 \\
\hline
\end{tabular}

Notes:

IN-EA: inflation rate that minimises $R P V$ using the optimal bandwidth obtained for the EA.

IN*: inflation rate that minimises $R P V$ using the optimal bandwidth for each country.

$b^{*}$ : optimal bandwidth for each country.

MSFE*: mean squared forecast error for optimal bandwidth for each country.

MSFE-EA: mean squared forecast error using the optimal bandwidth for EA.

MSFE is multiplied by $10^{6}$.

Regarding the optimal inflation rate as reported in Table 3, there is a discrepancy among countries. The results show that the ECB's "below, but close to 2\%" target is appropriate for the EA. However, this target is too low for Spain and too high for France and Germany. Therefore, although the ECB's target is indeed optimal for the EA as a whole, it may be hurtful for some countries.

As a robustness test we examine two sub-samples, the first and last ten year periods (Table 4). In particular, from Table 4 it is evident that the model is not sensitive to the time period selected, as the optimal inflation for the three countries does not change dramatically.

Table 4. Optimal inflation rates for different periods

\begin{tabular}{|c|c|c|c|}
\hline Period & Germany & Spain & France \\
\hline $1997.01-2006.12$ & 0.0054 & 0.030 & 0.009 \\
\hline $2001.01-2010.10$ & 0.012 & 0.030 & 0.014 \\
\hline
\end{tabular}

\section{Conclusions}

This paper examines the relationship between $R P V$ and inflation for selected EA countries using kernel regressions. The main finding is that the inflation-RPV relationship exhibits a U-shape functional profile and therefore there is a (non-zero) inflation rate that minimises the costs from inflation.

As to the actual optimal inflation rate found, it differs across the member countries. Using HICP data on a 3-digit level the results show that the ECB's target of an EA wide inflation rate "below, but close to $2 \%$ " is appropriate for the EA, too for Spain and too high for France 
and Germany. The results once again raise the question as to whether a common monetary policy is appropriate for the EA.

\author{
Acknowledgments \\ $\mathrm{M}^{\mathrm{a}}$ Ángeles Caraballo acknowledges financial support from Junta de Andalucía (CICE, Proyecto \\ de Excelencia SEJ-4546).
}

\title{
References
}

Barro R. J. (1976) Rational expectations and the role of monetary policy. Journal of Monetary Economics 2:1-32.

Bick A., Nautz D. (2008) Inflation threshold and relative price variability: Evidence from U.S. cities. International Journal of Central Banking 4:61-76.

Bruno M., Easterly W. (1998) Inflation crises and long-run growth. Journal of Monetary Economics 41:3-26.

Caplin, A. and Leahy,J. (1991) State Dependent Pricing and the Dynamics of Money and Output. Quarterly Journal of Economics 106: 683-708.

Caraballo M.A., Dabús C. (2008) The determinants of relative price variability: further evidence from Argentina. Cuadernos de Economía - Latin American Journal of Economics 45:235-255.

Caraballo M.A., Dabús, C. (2012) Optimal inflation, price dispersion and inflation: The Spanish case. Journal of Applied Economics (forthcoming).

Choi, C. (2010) Reconsidering the relationship between inflation and relative price variability. Journal of Money, Credit and Banking 42:769-798.

Cukierman A. (1983) Relative Price Variability and Inflation: a Survey and Further Results. In:

K. Brunner and A.H. Meltzer (eds.) Variability in Employment, Prices and Money, Elsevier, Amsterdam.

ECB (2004) The Monetary Policy of the ECB (second edition, January 2004). Frankfurt.

Fendel R., Frenkel M. (2009). Inflation differentials in the Euro Area: did the ECB care?.

Applied Economics 41:1293-1302.

Fielding D., Mizen P. (2008) Evidence on the functional relationship between relative price variability and inflation with implications for monetary policy. Economica 75:683-699.

Hercowitz Z. (1981) Money and the dispersion of relative prices. Journal of Political Economy 89:328-356.

Lucas R.E. (1973). Some international evidence on output-inflation tradeoffs. American Economic Review 63:326-335.

Nautz D., Scharff J. (2005) Inflation and relative price variability in a low inflation country:

Empirical evidence from Germany. German Economic Review 6:507-523.

Nautz D., Scharff J. (2012) Inflation and relative price variability in the Euro-area: Evidence from a panel threshold model. Applied Economics 44:449-460.

Parks R.W. (1978) Inflation and relative price variability. Journal of Political Economy 86:7995.

Rotemberg J. (1983) Aggregate consequences of fixed costs of price adjustment. American Economic Review 73:433-463.

Sheshinski, E. and Weiss, Y. (1977) Inflation and costs of price adjustment. Review of Economic Studies 44:287-303.

Vining D.R., Elwertowski T.C. (1976) The Relationship between Relative Prices and General Price Level. American Economic Review 66:699-708. 